\title{
A Study of Chinese-English Translation of Tourism Signs from the Perspectives of Skopos Theory
}

\author{
Yu Jia \\ Chongqing Normal University, China
}

\begin{abstract}
With the continuous improvement of China's overall national strength and the constant improvement of infrastructure, the national charm continues to increase. More and more foreign friends have been attracted to travel to China. The translations of public signs in scenic spots are of great importance for foreign visitors because of the language barrier and cultural difference existing between China and foreign countries. These translations should convey information accurately, providing the function of bringing convenience to visitors and spreading Chinese culture. However, in reality, there exist various problems among the translations of public signs in scenic spots, which will definitely make foreign visitors feel puzzled. So it is of great urgency to make the translation more standard. This study takes public signs of various scenic spots as the research material to explore the translation of the public signs of tourist attractions from the perspective of Skopos theory. This essay summarizes the errors and mistakes in the examples. By comparing and analyzing the unqualified translations in the examples and their polished versions, some specific translation strategies are proposed and explained in detail to provide useful guidance for the translation.
\end{abstract}

Index Terms - Skopos theory, tourism, public signs, Chinese-English translation

\section{INTRODUCTION}

Since reform and opening up in 1978, China's inbound tourism has witnessed a rapid development. The translation of public signs is particularly important for foreign tourists, it belongs to a kind of cultural communication with special purposes. A successful translation should be able to convey information accurately, bring convenience to visitors and spread Chinese culture. However, the traditional equivalence theory turns out to be increasingly inadequate and the rigid "faithful" translation will often produce negative effect. This paper aims to study Chinese-English translation using Skopos Theory, which believes that the purpose decides the translating strategies and methods. In this paper, I will also use the comparison method and the wrong analysis is a must.

As for the translation of public signs, dozens of domestic and foreign scholars have discussed them from different perspectives in recent years, focusing on the general types of public signs, including store names, roads and traffic signs and so on. However, the Chinese-English translation of public signs in scenic spots still lacks systematic researches, which cannot meet the demand of the rapid development of China's tourist industry.

\section{OverviEW OF PUBLIC SignS}

\section{A. The Definition of Public Signs}

"Public Sign" refers to a type of language used to achieve a certain kind of communicative purpose and provides people with information or guidance in public places so as to bring more convenience to people. They can be found almost everywhere. And the features of it are concise, allowing the readers to understand a message in a limited time. Sometimes it is accompanied by pictures to make it more specific and easy to understand. The bilingual public sign seems like a business card of the city and represents the image of the city today.

\section{B. Classifications of Public Signs}

According to the different purposes of public signs, we can divide the public signs into four categories based on the experiences of predecessors: Mandatory public signs, Promoting public signs, Restricted public signs and Directing public signs.

(a) Mandatory public signs:

The mandatory public signs have greater binding force on the relevant public. It demands that something must be done or must not be done with a forceful tone. Its tone is the strongest of all public signs and usually there is no room for other choices. It requires the public to implement, this kind of public signs often contain obvious words such as “禁 止”, “严禁”, “务必”, etc. And they are single, most of which are imperative sentences. More examples: "No Leaning"(请勿靠坐), “No climbing”(禁止攀爬)etc.

(b) Promoting public signs 
As the name implies, these slogans often have the function of reminding people to pay attention, but they do not force the public to take corresponding actions. Such public signs do not have any special meaning, they mainly serve as a reminder for tourists and tell tourists what they should do and how to do it. Promoting public signs are not mandatory, visitors can choose to adhere or not according to specific situations. For example: "Beware: falling stones or landslides." (小心石落, 小心滑坡). Other relevant slogans within the scenic area, " Caution: Radiation "(当心射线), “Downstairs here”(由此下楼),”Attend, Children”(请照顾好小孩).

(c) Restricted public signs

Restrictive public signs put forward requirements or constraints on the behavior of the public. The tone is straightforward, but it won't offend people and are not discourteous. For example, “Disabled only” (残疾人专用通 道),“No littering, please”(请勿乱扔垃圾), here “please”, the tone is obviously very polite. More examples: “Hot! Avoid contacting!",(菏! 别碰!). This sign aims at reminding the public to avoid burns, it is marked for personal safety, although the tone is a little bit straightforward and it makes people feel cared for rather than being offensive.

(d) Directing public signs

Such signs in scenic spots are to provide visitors with the necessary information. It does not target specific or individual groups and could give direction to us all. They do not convey mandatory information. People can purposefully obtain information provided by public signs according to their actual needs. It should be simple and concise, often expressed in static terms so that visitors can understand it at the first sight. For example, " way in" (景区 入口处), "ticket- checking" (入口验票), "Public Toilet"(公共则所), "Information"(问询处).

\section{SKOPOS THEORY}

Skopos is a Greek word for "purpose". Vermeer introduced it into translation theory in 1970. It reflects a general shift from predominantly linguistic and formal translation theories to a more functionally and socio-culturally oriented concept of translation. Just like any other human actions, translation has its own purpose or aim. Skopos theory is the most important one in functionalist translation theory. Hans Vermeer, Katharina Reiss, Jura Holz Manttari and Christiana Nord made outstanding contributions for the creation, development and improvement of the theory. It believes that there must be a clear purpose and intent before translating various texts. And three major principles are advocated, they are Skopos rule, coherence rule and fidelity rule. The Skopos rule is the first rule when translating, the other two rules must be subject to it. In other words, in order to achieve the purpose, translators can adopt strategies like rewriting, adding, deleting and sequencing flexibly and orderly.

\section{A. Three Principles of Skopos Theory}

Skopos rule is the primary principle of all translations. It means that we should enable the translation to function in the target context. Hans Vermeer classifies the purpose of translation into three types: the basic purpose of the translator, the communicative purpose of translation texts, and the purpose of the specific translation strategies. However, the term "Skopos" mainly refers to the communicative purpose of translation texts. (Nord,2001,p.27) According to Hans Vermeer, each translation is for a specific purpose and should achieve its purpose. To follow the Skopos rule in translation means that the translation should be able to meet the expectations of people in a particular cultural environment. Translation is just a kind of translation behavior based on the original text, translators should not see the original language and its function as standard, but focus on one or more communicative functions of the translation in the target language environment.

The second is the coherence rule. Hans Vermeer argues that a translation must meet the standard of "intra-textual coherence", the translation must be understood by the readers and be meaningful in the communicative context and in harmony with the reader's environment. Professor Changshuan Li (2012) believes that the coherence rule is to require "translation should be self-justifying" (p.11). This requires that the translator should fully consider the social and cultural background knowledge and psychological state of the target audience when translating, reducing the cultural barriers and making the translation comprehensible to the readers.

The last principle is fidelity rule. Vermeer believes that there is a corresponding relationship between the translation and the original text, he calls it "inter-textural coherence". It does not require the original text and the translation to be verbatim. The form and the degree of expression of fidelity depend on the translator's understanding of the original text and its purpose of translation. The translators have a moral responsibility to the recipients of the translations and must explain to them what they have done and the reasons for doing so. This is an aspect of fidelity. On the other hand, the principle requires the author to be loyal to the original author. The author should coordinate the target language and author's intentions on the basis of respecting the original author.

\section{B. The Relationship of Three Rules}

Skopos believes that the Skopos rule is the most important one, and it should be followed by all translations. If the Skopos rule requires that the original text and its translation to have different functions, then the rule of fidelity should not be applied. And the principle of coherence does not apply if the Skopos demands the translation not to be fluent (against "intra-textual coherence"). Therefore, inter-textural coherence is secondary to intra-lingual coherence and both 
of them are subordinate to the Skopos. The Skopos rule is universally applicable, and the other rules belong to special rules.

They are difficult to be taken into account together when translating. A feasible demand that the Skopos rule takes priority over the other rules. If the translation complies with fidelity rule and coherence rule but against the Skopos rule, such kind of translation is not appropriate. In contrast, if the translation is in accordance with the Skopos rule but against other rules, is this translation feasible? The answer is yes. So when there is a conflict between Skopos and the others, we must obey the former.

In short, the Skopos cares less about the equivalence of the translation and the original text or whether the translation is "perfect". Instead, it stresses that the translation should understand the purpose of translation clearly on the analysis of the original text and then choose appropriate translation strategies when translating so as to achieve the intended purpose.

\section{Some Translation ERrors of Chinese-English Public Signs}

The well-known German functionalist Nord (2001) holds the opinion that if the purpose of the translation is to enable the translation to achieve a specific function, all the ingredients that impede this goal are translation errors. The author divides errors into three types below.

\section{A. Pragmatic Translation Errors}

A pragmatic error means that people cannot understand what the words mean. For instance, someone translates “正 门"into" The positive Door,", but for the most part we use "positive" to modify attitudes and its antonym is "negative". Foreigners will feel puzzled if they are allowed to enter this door, so we'd better translate it as "Front Door".

Another example collected from Lijiang Scenic Area, the plaque of a silverware shop in the ancient city of Lijiang “民族银庄” was literally translated as "National Bank Village”. The word“银”'in the original text refers to "silverware" and it has no relation with "bank", and"庄" is actually a kind of store name, we can call it store or shop and it's obvious that village and shop are irrelevant.

\section{B. Cultural Translation Errors}

Nord (2001) believes that "Translating means comparing cultures". We should pay attention to cultural differences otherwise it will confuse tourists. For example, “寒山寺”is translated directly into "Cold Mountain Temple", actually more Chinese cultural background will be conveyed if we translate it as "Han Shan Temple" . We can always find that the translations of quite a few signs in the scenic areas look very good, but there is no explanation about the background, it will become harder for foreigners to comprehend. In the meanwhile, public signs cannot successfully present our Chinese culture.

Another example, “民族园”is translated as "Racist Park". The word "Racist" is full of racial discrimination and foreign tourists would feel disgusted at the first glance, let alone understand and accept it.

\section{Linguistic Translation Errors}

\section{Spelling errors}

Spelling errors could be easily found among the C-E translation of public signs. Misspellings not only fail to achieve the intended purpose, what's worse, these mistakes will not be conducive to the image of the scenic spot. Here are some examples collected in Fenghuang Ancient City:

“祖传手工银店”is translated as “ Inherited ManuaSilvner Shop”. The words "Manua” and "Silvner" cannot be written together, and there is an error in the spelling of both words. The correct one should be "Manual" and "Silver".

“小心碰头”Watch Your Head" is incorrectly written as "Watch Your Herd".

\section{Grammatical mistakes}

There are even some translations that are not sentences at all in the collected examples. Specific grammatical errors can be divided into noun singular and plural errors, verb tense errors, improper use of articles, punctuation errors, relative pronoun errors and so on. Take the following signs collected from Xiangshan for example:

“亲水区”is translated as “Close water Area”. The so-called “亲水区” is a place where visitors to easily get access to the water (such as streams, lakes, rivers, and the sea). The translator's thinking is correct, but it is not rigorous to simply put a verb and a noun together as an adjective. It is recommended to change it to “Close-to-water Area”. “可回收 物" and its translations "Recyclable" are marked on the trash bins there. There are many types of recyclables, so the "Recyclable" here should be "Recyclables"

\section{Causes of Errors}

The author believes that the reasons for the translation problem can be analyzed mainly from three levels: the translator, the scenic spot, and the relevant authorities.

First of all, the translators play a crucial role in determining the quality of translation, and their language skills must be brilliant. From the numerous spelling and grammatical errors in the collected examples, it can be inferred that the 
relevant translator's basic language skills are likely to be unqualified. The second reason is lacking relevant cultural background knowledge. Translation is a cross-cultural behavior and every language is closely linked to the culture behind it. Therefore, if you want to effectively communicate between different languages, you must understand the culture of both countries. Only in this way can translators accurately understand the original text and translate it accurately. Third, the appropriate translation theory and translation strategies also function in translation. Fourth, the vast majority of low-level language errors may not be placing most of the blame on translators' language skills but his attitude. A rigorous and serious attitude and a strong sense of responsibility are necessary qualities that a qualified translator should possess.

For scenic spots, it is impossible that they cannot afford to hire the qualified translators. Then the reasons can be classified into two groups. First, the scenic spot itself has no ability to judge the quality of the translation. The second is the insufficient attention paid to the translation of public signs. For the former, the scenic area can employ relevant professionals including native speakers for translation and proofreading. For the latter, the scenic spot has to strengthen the awareness that the translation of public signs is an important part of the scenic spot service.

So many kinds of errors exist in various tourist attractions. Obviously, the relevant tourism authorities are to blame. For authorities, they can take some actions such as formulate local translation specifications for public signs. There are many domestic cities that can serve as models, in those cities, the quality of translation has been taken into consideration when evaluating the level of scenic service. And they also mobilize the local college students to give suggestions on it.

\section{STRATEGIES FOR TOURISM SignS TRANSLATION}

\section{A. Borrowing}

Borrowing strategy is one of the most commonly used strategies for translating public signs. The history of usage of public signs in the western countries is longer than that of China, so some signs are more standard. Therefore, they can be borrowed directly if expressions with the same meaning and function can be found. Although there are great language and cultural differences between two languages, some similarities still exist. In this way the reader's reading comprehension barrier can be reduced so as to achieve the purpose of communication better, meanwhile it also does not violate the fidelity principle.

For example, “绿色通道” this public sign is common. It refers to a special channel setting for those people who need it. Therefore, we can borrow its corresponding expression "Priority Lane".

Another example from Lingyin temple:

The original text:花草有生命, 慈悲呵护。

The translation: Flowers of life, compassionate care.

Although the original tone of this example is very euphemistic, it is a restrictive public sign in essence. It is obvious that the translator consciously complied with the linguistic characteristics and requirements of the public sign, but he still translated it word by word. It is unsurprisingly that the translation could not achieve the purpose of communication. When translating, translators should not be constrained by the specific expression of the original text, but should extract the true purpose of the information. The real purpose of the original text is to inform tourists not to trample flowers. The best way is to borrow the existing usage of English conventions: Please Keep off the Grass.

One more example is the common “温馨提示” in Chinese Scenic areas, it is translated into "Warm Prompt" in most of the scenic area. The noun "prompt" has the similar meaning with "remind”. Actually public signs like“温馨提 示”belong to the warning message. If you search for "warm prompt" in Google, you would find there is no example in any English-speaking country. The author also found such problems in the foreign net forums, this also confirms the word" warm "does not conform to the English habits and it makes people feel incredible. So if the original text belongs to warning information, it can be directly translated as "Warning" or "Attention".

\section{B. No Translation}

At present, some common Chinese public signs cannot find any traces in English-speaking countries. Some of the public signs are completely set for our own citizens. In this case, translators should consider whether it has the necessity to translate it. Such as “商品售出后一概不换” in the store, and “违者罚款” which can be seen in most places. Here the author lists some situations when we have no need to translate them.

The first type is "Call-to-action signs". This kind of signs is set up for Chinese people. Translating it into English will make foreigners think that it is a request to them from the government, so we don't need to translate it. Such as “争创一 流城市”, “全心全意为人民服务”, etc.

And the second type is the sign which is closely related to specific cultures. A sign is placed at the entrance of the parking lot of Tamsui Temple, a well-known scenic spot in Beijing: “Military vehicles without charge”.(军车免 费) .Obviously, this translation is terrible and there are many kinds of mistakes. We should translate it as "Free parking for military vehicles." We think about this carefully: Is it necessary or suitable to translate this brand into English? Will foreign military vehicles drive to Beijing? Will the foreigner's cars in China use military license? 
What's more, in the store near the Nanjing Confucius Temple, there is a sign saying "本店无假货" We'd better not to translate such public signs. It is against morality and law to sell fake commodities. If such signs are translated, it will definitely impair the image of the country. Another example can be easily found in many restaurants is “谢绝自带酒水”. This actually violates the rights and interests of consumers.

\section{Annotation}

The scenic public signs of some historical sites may inevitably involve historical and cultural knowledge. In the process of such translations, we must always remember two points. First, translators should try to treat the original text from the perspectives of foreign tourists. In this way, we will find that foreign tourists are not familiar with many common backgrounds that we take for granted or are even hearing it for the first time. Second, most of these public signs have the function of education, bearing the function of presenting and spreading Chinese culture at the same time. It is quite different from prompting and restricted public signs which only provide information. Above all, it is still not enough to accurately translate the original text in such public signs. The translator should add some notes. Here the author list three situations that need to be noted:

The first situation is when involving the translation of the dynasty. Take“龙华寺”, one of the oldest temples in Jiang Nan region for example:

The original text: “此寺在宋朝时期修建”

The translation: "It was renovated during Song Dynasty."

The name of the dynasty in this example, for Chinese tourists, we have a general concept of the order and time of these dynasties. However, foreigners never hear the expressions before. Therefore, we'd better add notes such as A.D. or B.C. behind the dynasty so as to make them understand better.

Second, when involving the name of the city in history, the current name should be added.“中州油梁” in Millennium City Park, it was translated into "Bian Liang of Central Plains" Historically, Kaifeng was once known as“泣梁”、“沛州”etc. Translations should retain the original name and add a note indicating that this was the name of Kaifeng at the time. So the better version should be"Bian Liang of Central Plains"(the name of Kaifeng in Song Dynasty)

The third type is involved with historical figure. “张龙、赵虎、王朝、马汉” are mentioned in the brief introduction of “包公迎宾”, a historical and cultural characteristic show in Millennium City Park. They are four guards in Kaifeng Mansion. However, the corresponding translation is "Zhang Long, Zhao Hu, Wang Chao and Ma Han". It seems that they are ordinary people, and the foreigners will certainly feel curious about who these four people are and why they write their names one by one. Therefore, translations should add some explanations. Otherwise, it will fail to achieve the goal of cultural communication.

\section{Omission}

Omission means we can omit some words in order to make the translations more clear and brief. English public expressions are usually concise, intuitive and clear. Foreigners care more about practicality. However, Chinese public expressions often contain more details and subjective emotions. The difference between the two determines that the translator should delete unnecessary Chinese information according to the foreigner's culture while translating. Here is an example from the Yuntai Garden:

The original text:爱护花草, 请勿穿行。

The translation: Protect flowers and plants, no passing through.

The original text is antithesis which is commonly used in Chinese. It looks neat and beautiful and reads well. Regardless of the grammatical errors, the first half "protect flowers and plants" is obviously unnecessary, because all of us know that the prohibition of walking through is to protect flowers and plants, it will appear more authentic if omitted.

Another public sign in the Double Dragon Cave:“青青花草, 请勿践踏”, it is translated as "Green Grass, Do not Trample", it is exactly the same problem as the first example. “小草对您微微笑, 请您把道绕一绕”is translated as "Please Walk for other Ways instead of Trampling the Grass". Compared with the first two cases, it is comforting the translator knows that there is no need to translate“对您微微笑”, but the translation of the latter part of the sentence is still too close to the literal translation, without trampling on the lawn, the only way is to detour, so " Please Walk for other Ways" is obviously a burden to understand.

The author discovered during the investigation that when depicting the scenery, the Chinese particularly like to use some gorgeous words and rhetoric. It's so nagging. If these descriptions are translated into English completely, there would be a lot of redundant information. For Chinese people, they tend to deepen the impression and gain artistic enjoyment, but for foreigners, these seem to be superfluous.

\section{E. Transliteration and Literal Translation}

This strategy involves many terms with Chinese cultural information. This kind of public signs are conducive to cultural transmission. Transliteration alone or literal translation alone can not completely convey the language and cultural connotation of the original text, so we'd better combine them. Generally these can be divided into two 
categories:

The first type is the name of the places of interest. For example, there is a public sign on the edge of the estuary of the Imperial River Scenic Area.

The original text: “集锦园、春花园、夏荫园、秋韵园、冬凝园”

The translation: Jijin Garden, Chunhua Garden (Spring Garden), Xiayi(Summer Garden), Qiuyun Garden (Autumn Garden), Dongning Garden(Winter Garden).

First of all, it is advisable to add Hanyu Pinyin so that foreign tourists can both enrich Chinese knowledge and understand Chinese culture more comprehensively. Secondly, in the translation in parentheses, the translator did not entangle with the correspondence of the words, namely“花”, “荫”矢凝”. Actually, what it wants to express is that there is a view of the four seasons in these gardens. The translator has accurately understood the original text and made a simple expression of information. The translated version presented is not only appropriate for Chinese cultural characteristics but also consistent with English expression.

However, in the actual investigation, the author found that most of the cases were only completely translated into English without pinyin. The author believes that if the translation aims to achieve its cultural communication effectively, it should be supplemented with Hanyu Pinyin. In this respect, the translations in the Palace Museum can be used as a benchmark for reference. The following examples are from the official website of the Forbidden City:

午门:Meridian Gate (Wu men)

乾清宫:Palace of Heavenly Purity (Qianqing gong)

The second type is the alias of a historical figure or other specific titles, some examples in the introduction of the Baogong Scenic Area:

原文:包拯被尊称为“包青天”。

译文:Bao Zheng is respectfully called "Bao Qingtian" (Justice Bao).

Bao Qingtian is recognized as the most famous figure in Kaifeng. In Chinese, "Qingtian" has a metaphor for honesty. Therefore, it is appropriate to translate "Bao Qingtian" into "Justice Bao". Combining it with transliteration can enrich and deepen foreign visitors' cultural experience.

原文:北宋一代，从这里曾先后考出过三十多名状元.....

译文:In the Song Dynasty, in this building there were more than 30 examinees becoming the Top Graduates who were called Zhuang Yuan in Chinese.

In this translation, the combination of transliteration and literal translation clearly convey the concept of "状元" in Chinese, which is smooth and clear.

\section{SUMMARY}

The translation of public signs plays a significant role in today's tourism. Compared with travel brochures, maps, leaflets, public signs are more noticeable. The quality of translation not only directly affects the tourists' feelings about the tourist destinations, but also affects the tourists' impressions of the place or the country, and indirectly affects the development of the tourism in the area or the country. It serves as an important indicator reflecting the service quality of scenic spots. Unfortunately various errors and problems still exist in the English translation of public expressions of scenic spots.

In conclusion, this paper analyzes the translation of public signs in scenic spots from the perspective of Skopos theory. First of all, it makes a brief introduction of the definition and the categories public signs. Second, the Skopos theory and its three principles are introduced clearly. Then the author classifies and analyzes translation errors in public expressions with explanation of their reasons on the basis of a large number of examples. Finally, the author proposes some appropriate strategies to solve problems based on the Skopos theory. The author believes that when translating, the purpose and requirements of translation are taken as the first issues to be considered, translators should abide by the three principles of Skopos theory and adopt appropriate translation strategies so as to make the translation of public signs in scenic area more appropriate and acceptable.

\section{REFERENCES}

[1] Changshuan Li. (2012). Theory and Practice of Non-literary Translation. Beijing: China Translation \& Publishing Corporation.

[2] Chenxiang,Zhang. (2008). The Functionalist Skopos Theory and pragmatic Translation. Shangsha: Hunan Normal University Press.

[3] Katharina, Reiss. (2004). Translation Criticism: The Potentials \& Limitations. Shanghai: Foreign Language Education Press.

[4] Nord, Christiane. (2001). Translating as a Purposeful Activity: Functionalist Approach Explained. Shanghai: Shanghai Foreign Language Education Press.

[5] Vermeer, Hans J. (1987). What does It Mean to Translate? India: Indian Journal of Applied Linguistics.

[6] Xiang, Zhao. (2006). Cultural Differences between Chinese and English Logos and Pragmatic Translation. Foreign Language Education, (2), 72-74.

[7] Yin,Wang \& Hefa,Lu. (2006). Chinese-English Translation of Signs. Beijing: China Translation \& Publishing Corporation.

[8] Yali, Zhang. (2016). Investigation Report on the Status Quo of English Translation of Public Signs in Shanxi Province. Journal 
of Longdong University, (11), 31-32.

Yu Jia was born in Zhejiang, China in 1996. He is currently a post-graduate student in linguistics in Chongqing Normal University, China.

During the post-graduate, he held the post of English Teacher for public English college students in Chongqing Normal University for one term in 2019. He has been working as a part-time job teacher in Education Institution for 6 years. 